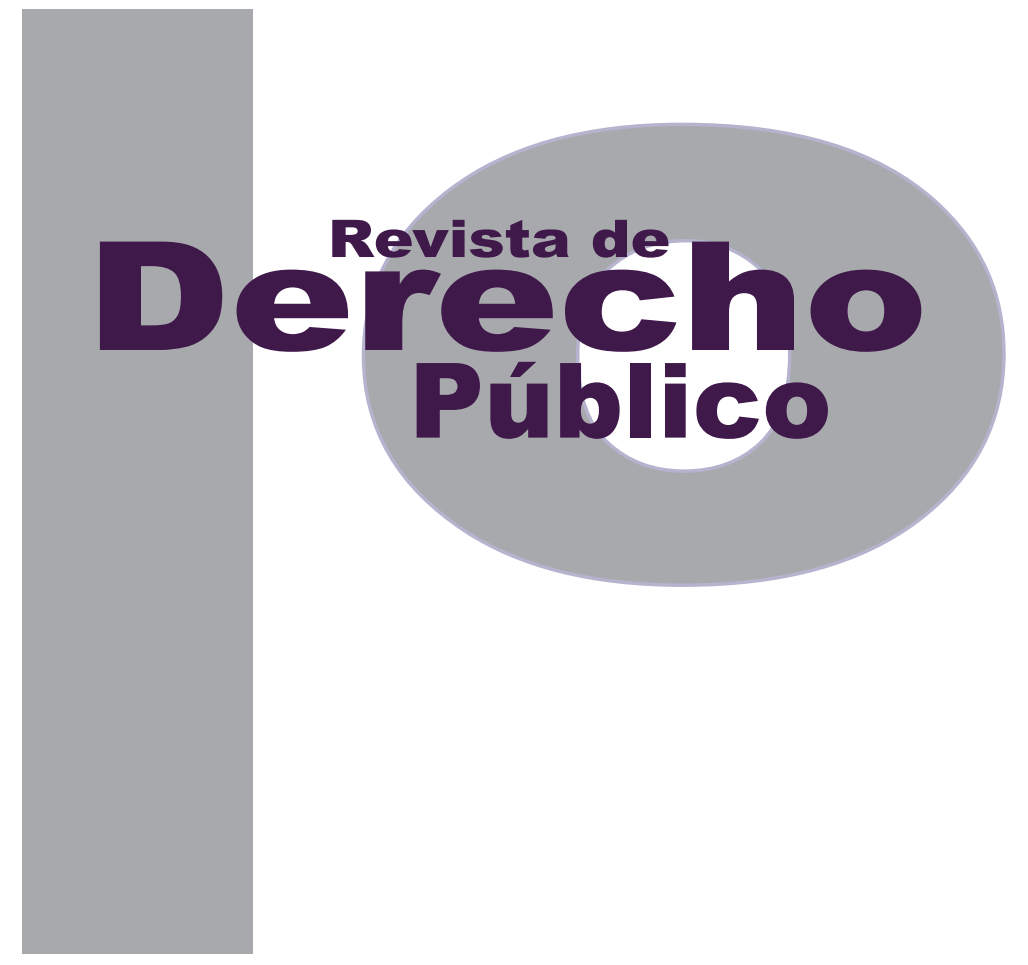

ASOCIACIONES PÚBLICO PRIVADAS, MODELO DE DESARROLLO DE INFRAESTRUCTURA PRODUCTIVA Y SOCIAL EN COLOMBIA Y EL MUNDO: MARCO HISTÓRICO, CONCEPTUAL Y CRÍTICO DE LA LEY 1508 DE 2012

Matías LoNdoño VALLEJo

DOI: http://dx.doi.org/10.15425/redepub.33.2014.08

Universidad de los Andes

Facultad de Derecho

Revista de Derecho Público N. ${ }^{\circ} 33$

Julio - Diciembre de 2014. ISSN 1909-7778 


\title{
Asociaciones público privadas, modelo de desarrollo de infraestructura productiva y social en Colombia y el mundo: marco histórico, conceptual y crítico de la Ley 1508 de 2012
}

\section{Resumen}

Este escrito presenta un análisis de la figura de las APP (asociaciones público privadas), primero desde una perspectiva histórica e internacional, y luego en tiempo presente aplicada al plano nacional. Puede encasillarse como un artículo de reflexión o de revisión, ya que por un lado se hace una crítica a las APP, pero por otro se realiza una revisión sobre estas en el escenario jurídico nacional.

Al abordar las diferentes concepciones y tipologías de las APP se muestra que la figura varía según los diferentes ordenamientos jurídicos, que no es tan novedosa como se piensa, sino que es un esquema de contratación que se ha venido desarrollando en el tiempo.

Por último, se expone el concepto de las APP dentro de la Ley 1508 de 2012 y se plantean, desde un punto de vista crítico, unas posibles dificultades y problemas que la Ley puede representar dada la forma en la que fue concebida por el legislador.

Palabras clave: infraestructura, asociaciones público privadas, servicios, Ley 1508 de 2012, contratación estatal, transferencia de riesgos, capital privado, inversión, infraestructura social, infraestructura productiva, financiación, presupuestos, recursos.

\section{Public private partnerships, productive and social infraestructure development model in Colombia and the world: historical, conceptual and critical framework of the law 1508 of 2012}

\begin{abstract}
This paper aims to develop an analysis of the PPP (Public private partnerships) viewed, at the beginning, from an historical and international perspective and then analyses this figure in the national scene at present time. This paper may being enclosed as a reflection paper or a review paper, since on the one hand generates a critique of the figure and in the other hand, makes a revision of the figure of the Public Private Partnership in the national scene

The text addresses the different conceptions and typologies of the PPP, showing the difference of the figure depending the legal system where is developed, and demonstrating that is not a new figure, but a scheme that has been developing from several years ago.

Finally, this paper develops the concept of the PPP inside the law 1508 from 2012 and establishes, from a critical perspective, some possible problems that the law could develop.

Keywords: infrastructure, public private partnership, services, law 1508 from 2012, public tendering, transfer of risks, private equity, investment, social infrastructure, productive infrastructure, financing, budget, resources.

\section{Associações público privadas, modelo de desenvolvimento de infraestrutura produtiva e social na Colômbia e no mundo: marco histórico, conceitual e crítico da Lei 1508 de 2012}

\section{Resumo}

Este escrito apresenta uma análise da figura das APP (associações públicas privadas), primeiro desde uma perspectiva histórica e internacional, e depois em tempo presente aplicada ao plano nacional. Este pode ser enquadrado como um artigo de reflexão ou de revisão, já que por um lado é feita uma crítica às APP, mas por outro é realizada uma revisão sobre estas no cenário jurídico nacional.

Ao abordar as diferentes concepções e tipologias das App é mostrado que a figura varia segundo os diferentes ordenamentos jurídicos, que não é tão inovadora como se pensa, senão que é um esquema de contratação que vem sendo desenvolvido com o tempo.

Por último, é exposto o conceito das APP dentro da Lei 1508 de 2012 e se explicam, desde um ponto de vista crítico, as possíveis dificuldades e problemas que a Lei pode representar dada a forma na qual foi concebida pelo legislador.

Palavras-chave: infraestrutura, associações públicas privadas, serviços, Lei 1508 de 2012, contratação estatal, transferência de riscos, capital privado, investimento, infraestrutura social, infraestrutura produtiva, financiamento, orçamento, recursos. 


\title{
Asociaciones público privadas, modelo de desarrollo de infraestructura productiva y social en Colombia y el mundo: marco histórico, conceptual y crítico de la Ley 1508 de 2012*
}

\author{
Matías Londoño Vallejo**
}

\section{SUMARIO}

Introducción - I. ¿QUÉ ES UNAASOCIACIÓN PÚBLICO PRIVADA? - A. Su origen internacional - B. Razones para su adopción - 1. El apretado presupuesto al cual están sometidos algunos países alrededor del mundo - 2. La planeación - 3. La innovación - II. LAS APP EN COLOMBIA - A. APP de iniciativa pública - B. APP de iniciativa privada - C. Breve aclaración sobre las fuentes de financiación de las APP en Colombia - D. Diferentes aspectos, comentarios y controversias generadas por la implementación del modelo de APP en Colombia - 1. Controversia generada por la calidad de los aportes públicos frente al tope impuesto por la Ley 1508 en su artículo 17 - 2. Diseño de la Ley 1508 como traba para el desarrollo de los proyectos de APP de infraestructura social - 3. Cruce de proyectos en la infraestructura vial desarrollada a través de APP - III. CONCLUSIONES - Referencias.

* Cómo citar este artículo: Londoño Vallejo, M. (Diciembre, 2014). Asociaciones público privadas, modelo de desarrollo de infraestructura productiva y social en Colombia y el mundo: marco histórico, conceptual y crítico de la Ley 1508 de 2012. Revista de Derecho Público, 33. Universidad de los Andes (Colombia).

** Abogado de la Universidad de los Andes. Actualmente se desempeña como abogado del área de contratación estatal, derecho administrativo e infraestructura de la firma Cárdenas \& Cárdenas Abogados. Con anterioridad trabajó en Gómez-Pinzón Zuleta Abogados en el área de derecho corporativo con énfasis en la práctica inmobiliaria. Durante su formación académica se desenvolvió como monitor de diferentes cursos, entre ellos, Derecho Penal Especial y Constitución y Democracia. Correo: matiaslondono@gmail.com 


\section{Introducción}

Durante varios años el país ha sufrido una problemática compleja en torno a la contratación estatal, producto de haberse estado moviendo entre el despilfarro de los recursos públicos y la ineficiencia administrativa. Por tal motivo, resulta alentador y esperanzador que se generen propuestas que permitan darle solución a las dificultades que aquejan al Estado y principalmente a sus finanzas. Se podría asegurar que parte de la solución a los problemas antes mencionados se encuentra contenida en la Ley 1508 de 2012, por medio de la cual se propone un modelo novedoso de desarrollo de obras de interés nacional.

Por lo anterior, en este escrito se tocan varios puntos de fondo relacionados con dicha ley, como los orígenes de la figura de las asociaciones público privadas (APP) desde sus inicios en el exterior, y las distintas tipologías que adquieren en diferentes lugares, para luego verlas en Colombia donde acaban de aterrizar, y determinar claramente qué son, cuál es su objetivo y qué tipos contempla la Ley 1508.

Se concluye planteando tres aspectos precisos en los cuales el autor considera que hay algún tipo de controversia en la mencionada ley: el problema relativo a la participación financiera que el Estado puede llegar a tener en los proyectos, el estar diseñada de tal modo que impide a los particulares proponer al Estado la construcción de obras de infraestructura social bajo dicha figura y el problema que plantea el cruce de proyectos/concesiones antiguas con las nuevas concesiones.

\section{I. ¿QUÉ ES UNA ASOCIACIÓN PÚBLICO PRIVADA?}

Según el artículo 1 de la Ley 1508 de 2012 las asociaciones público privadas son instrumentos de provisión de bienes públicos y servicios relacionados, los cuales se desarrollan a través de la celebración de contratos entre particulares/ entes privados y la Administración.

Lo particular de esta relación jurídica entre las partes mencionadas es que supone cambios en las formas tradicionales en que se desenvolvían temas propios de la contratación estatal como: la retención y transferencia de riesgos entre las partes frente al proyecto, y los mecanismos de pago de acuerdo con la disponibilidad y el nivel de servicio de la infraestructura o servicio.

Así, las APp son contratos económicos a largo término que pretenden la provisión de bienes públicos y los servicios que se relacionan con estos (Greve, 2010, p. 585). Dichos contratos económicos se desarrollan entre el Estado y personas naturales o jurídicas de derecho privado que retienen o transfieren los riesgos del proyecto (Conpes, 2009). Ciertos autores sintetizan el concepto de las APP como una forma de colaboración contractual entre los sectores público y privado, en la que ambos actúan conjuntamente para el logro de un objetivo que sería imposible conseguir por separado (Ariño Ortiz, 2010, p. 203).

Pero la figura es aún más complicada, ya que supone la aplicación de complejos modelos de financiación y desarrollo de obras. Dichos mo- 
delos establecen una clara y estricta planeación de los proyectos, donde se evalúan las contingencias que su ejecución pueda suponer; además, fijan los mecanismos de pago directamente relacionados con la disponibilidad, los estándares de calidad y el nivel de servicio de la infraestructura.

Las APP aplican para todo tipo de infraestructura productiva (incluyendo la relacionada con la prestación de servicios públicos) y social. A grandes rasgos, requieren el encargo de una entidad estatal a un privado para: 1) diseño y construcción de infraestructura; o 2) construcción, reparación, mejoramiento o equipamiento de infraestructura. En ambos casos deben incluir operación y mantenimiento. Sin la operación y el mantenimiento no hay lugar a la APP.

\section{A. Su origen internacional}

En el Reino Unido, a finales de los años setenta y principios de los ochenta, producto de la crisis de las empresas públicas que a su vez iba acompañada de otros fenómenos como la altísima inflación y la caída del producto interno bruto (PIB) se genera en el imaginario colectivo y en la práctica administrativa la idea de que el sector privado utilizaba mejor los recursos económicos y era más eficiente que el sector público en la gestión empresarial. Por tal motivo, y bajo los mandatos de la primera ministra Margareth Tatcher, aparecen las Public-Private Partnerships (Ariño Ortiz, 2010, p. 203), en español asociaciones público privadas (APP). En un principio, estas asociaciones fueron concebidas como el camino intermedio entre la estatización y la pri- vatización (Taylor, 1999), pero ante todo como una de las medidas para la reactivación de la economía, la reducción de la carga del Estado y el aumento de la productividad y ejecución de las actividades propias del sector público.

Antes de la existencia de las APP, en Colombia la infraestructura y los servicios eran administrados, operados y explotados por el Estado. Sin embargo, las obras públicas no fueron las únicas que estuvieron sometidas al régimen de administración estatal, también los servicios sociales de toda índole, entre los que se pueden encontrar la educación, la sanidad, la protección social, entre otros (Palacio, 2002, p. 204).

La transición del modelo estatal, a uno en el que el privado tiene una mayor participación, también comienza cuando en el sector de infraestructura y servicios públicos se empieza a requerir un esfuerzo financiero y de inversión que el erario público es incapaz de atender (Palacio, 2002, p. 204). El fenómeno se dio tanto en economías evolucionadas y desarrolladas como también en emergentes y en desarrollo. En las primeras, porque el crecimiento del gasto social las hace incapaces de soportar las inversiones que deben realizar con ahorro público y sin la imposición de nuevos impuestos (Greve, 2010, p. 588), y en las segundas porque la ineficacia administrativa del Estado y las inmensas cargas financieras no son posibles de sobrellevar con los modelos administrativos vigentes en ese momento (Ariño Ortiz, 2010, p. 204).

Frente a la necesidad de mantener unos bajos niveles de déficit fiscal, sumada a la necesidad 
de generar desarrollo en infraestructura y servicios sociales que permita hacer frente a los desafíos sociales y de infraestructura, los Estados dirigen sus miradas a la inversión privada que se representa principalmente en las instituciones financieras, ahorro privado y mercado de capitales que son las fuentes de capitalización y de recursos para dichos proyectos (Villanacourt, 2000, p. 15).

En ese sentido, se presenta una tensión entre la necesidad de infraestructura y la imposibilidad financiera, operativa y administrativa de los Estados. Dichas necesidades llevan a buscar nuevas fórmulas por medio de las cuales hacer alianzas entre el sector público y el sector privado de una manera armoniosa, que permitan vincular el capital privado y retener o transferir los riesgos que las obras y la prestación de los servicios suponen.

Esta herramienta de desarrollo de infraestructura y prestación de servicios ha generado diversos debates entre aquellos que la defienden argumentando que "es una amplia revolución mundial en provisión de infraestructura y Project finance" (Grimsey, 2004) y quienes la denominan pink privatization (Jordana y Levi-Faur, 2004, pp. 10, 24) haciendo referencia a que son expresiones eufemísticas usadas sutilmente para privatizar el sector de la infraestructura y los servicios públicos.

Pero la pregunta fundamental es: ¿por qué los gobiernos se interesan realmente por adoptar esta figura? La respuesta muestra varios factores.

\section{B. Razones para su adopción}

\section{El apretado presupuesto al cual están sometidos algunos países alrededor del mundo}

Esta situación ha hecho que las APP se conviertan en un salvavidas para poder construir nuevos proyectos sin que los gobiernos se vean en la obligación de incrementar los impuestos a los ciudadanos, argumento económico muy importante para estimarlas una herramienta útil (Greve, 2010, p. 588). En palabras de Yescombe, “evadir las limitaciones del presupuesto es el factor fundamental para dar explicación al crecimiento de la práctica de la contratación bajo el modelo de APP" (2011, p. 15).

\section{La planeación}

Dado que bajo el modelo de las App la responsabilidad de los privados aumenta, estos deben desarrollar estrictos análisis de costos que incluyan todas las posibles contingencias en las que el proyecto puede incurrir. En todos los tipos de APP el sector privado (inversores y prestamistas) asume riesgos de capital y por ello tiene un gran incentivo financiero para asegurar que los servicios que prestan se den de la manera en que son requeridos (Yescombe, 2011, p. 24). En caso de no cumplir con los estándares de calidad establecidos al momento de la adjudicación, el privado no podrá iniciar la explotación de la obra, por tal motivo debe desde el principio organizarse de manera que pueda saber a ciencia cierta en qué momento debe estar la 
obra lista para empezar a recibir ingresos sobre esta. En el aspecto de planeación es necesario resaltar que la APP establece mecanismos jurídicos que aseguran los recursos a través de patrimonios autónomos con una única destinación de desembolso de recursos.

\section{La innovación}

Las APP combinan las ideas y la experiencia del sector público y el sector privado para el desarrollo de los proyectos. Esto es lo que en Europa se ha denominado competitive dialogue (Greve, 2010, p. 591), que en últimas consiste en que las partes dialoguen sobre los términos, condiciones y estructuración del proyecto bajo ciertas condiciones. Este aspecto las muestra como una forma contractual menos estricta que la que se usaba antes, cuando la entidad estatal no contaba con el concepto del particular para la estructuración del proyecto (Greve, 2010, p. 592). Es necesario recalcar que en los modelos de contratación estatal clásica, si bien los contratos son acordados entre las partes en virtud del principio de autonomía de la voluntad, quien tiene la iniciativa sobre el objeto y la necesidad es el organismo público. ${ }^{1}$ Con las App se le da al privado la posibilidad de tener iniciativa propia en cuanto a los proyectos que se van a realizar.

1 En Colombia, antes de la Ley 1508 ya se usaba la iniciativa privada como mecanismo promotor de proyectos. Por ejemplo, el artículo 32 de la Ley 80 de 1993 en su parágrafo $2^{\circ}$ establecía que: "Las personas interesadas en celebrar contratos de concesión para la construcción de una obra pública, podrán presentar oferta en tal sentido a la respectiva entidad estatal en la que se incluirá, como mínimo, la descripción de la obra, su prefactibilidad técnica y financiera y la evaluación de su impacto ambiental".
En el ámbito internacional se han comenzado a desarrollar diversas modalidades y expresiones de las APP, que por lo general son producto de las diferentes necesidades de los Estados, las características de los inversores y los distintos sistemas jurídicos, como lo muestran los escritos de diferentes autores.

Rodal y Mulder (1992, p. 3) las organizan en tipologías según el reparto de potestades entre los agentes participantes: 1) consultivas: las entidades públicas reciben asesoramiento para la obtención de conceptos y desarrollos que nutran de ideas el desarrollo de políticas y programas de actuación públicos y para el diseño, prestación, evaluación y corrección de servicios; 2) contributivas: uno de los agentes aporta fondos económicos, con una escasa o nula participación en la fase operativa, liberando recursos para la prestación de otros servicios; 3) operativas: los agentes participantes comparten recursos y tareas e intercambian información en la prestación de servicios; 4) colaboradoras: fomentan la toma de decisiones conjuntas con respecto al desarrollo de políticas, planteamientos estratégicos y diseño, prestación, evaluación y mejora de servicios.

A diferencia de los planteamientos teóricos ya descritos, The National Council for Public-Private Partnership (NCPPP) ${ }^{2}$ (1999) de los Estados Unidos ha determinado múltiples y variadas formas de asociaciones entre Estado y particulares para el diseño, financiación, construcción, man-

\footnotetext{
2 Consejo Nacional para las Asociaciones Público Privadas de los Estados Unidos.
} 
tenimiento y gestión de obras, entre las cuales cabe resaltar:

O\&M (operation and maintenance/operación y mantenimiento): son contratos en los que el Estado como socio contrata con el particular el mantenimiento de un servicio específico. Bajo la operación y el mantenimiento del privado, el Estado conserva el dominio de la totalidad del manejo del sistema.

OMM (operation, maintenance and management/operación, mantenimiento y gestión): en esta modalidad de cooperación contractual entre públicos y privados, el Estado mantiene el dominio de la totalidad del manejo del sistema, pero la parte privada debe invertir sus propios recursos en este. Cualquier inversión privada es cuidadosamente calculada en relación con la ganancia de una operación eficiente y los ahorros que se puedan generar durante el transcurso del contrato. Generalmente, cuanto más extenso sea el contrato mayor posibilidad hay de aumentar la inversión privada al haber más tiempo para recuperar dicha inversión y generar ganancia. Este modelo es comúnmente usado en los Estados Unidos para la prestación del servicio de tratamiento de aguas residuales. El modelo antes expuesto se asimila a la generalidad de las APP en Colombia, ya que se siguen parámetros parecidos.

DBOM (design-build-operate-maintain/Diseño, construcción, operación y mantenimiento): este modelo de alianza combina el diseño y la responsabilidad de la construcción con la operación y el mantenimiento. Los proyectos bajo esta modalidad son desarrollados por el sector privado en un solo contrato con un aseguramiento financiero del sector público. El sector público mantiene el dominio y la supervisión constante de la obra.

España ha optado también por las APP, o como ellos la llaman: colaboración público privada (СРP), con base en las diferentes tareas que se pueden desarrollar con dicho mecanismo. Según la necesidad usan un modelo de cpp diferente para cada situación.

Colón de Carvajal (2013) presenta así las diferentes modalidades:

BOT (Build Operate and Transfer/Construcción, operación y transferencia): el sector privado se compromete a construir un proyecto diseñado por la propiedad de este (en el caso de infraestructuras públicas, la administración pública), buscando para ello la financiación necesaria, y a explotarlo durante un periodo de tiempo, fijo o variable, acordado contractualmente. Transcurrido dicho plazo, el derecho a explotar el proyecto revierte de nuevo a la propiedad, que puede decidir seguir explotándolo por sí misma o volver a transferirlo al sector privado.

BOOT (Build, Own, Operate, Transfer/construcción, dominio, operación y transferencia): es un sistema básicamente igual que el anterior, pero con la diferencia de que lo construido pasa a ser propiedad del sector privado que lo explota hasta el momento en que revierte, lo que se traduce en una mayor garantía para dicho consorcio. 
BOO (Build, Own, Operate/construcción, dominio y operación): la diferencia con el modelo anterior es que en este sistema no se produce la transferencia final de los activos, generalmente porque su periodo estimado de vida útil coincide aproximadamente con el tiempo de explotación necesario para financiar su construcción y operación. Suele utilizarse para la explotación de recursos no renovables, que suponen la explotación total hasta su agotamiento, punto en el cual ya el contrato se termina.

DBFO (Design, Build, Finance, Operate/diseño, construcción, financiación y operación): es muy parecido al modelo BOT, con la diferencia que en este caso el sector privado debe asumir también el diseño del proyecto. La propiedad de los activos permanece en todo momento en manos de la administración pública, remunerando esta al consorcio privado encargado de explotar el proyecto a través de la modalidad de peaje sombra.

Las formas expuestas anteriormente son una pequeña muestra de la enorme variedad en la aplicación de los modelos de APP en el mundo y su adaptabilidad a las necesidades del momento. Es importante aclarar que los modelos de los países expuestos difieren de la concepción colombiana en el sentido en que hay más diversidad en las formas de contratación que las APP permiten usar.

\section{LAS APP EN COLOMBIA}

Las APP han estado por varias décadas en la agenda política de distintos gobiernos alrededor del planeta. La historia de la colaboración entre particulares y entes públicos data de mucho tiempo atrás, pero solo hasta ahora se está consiguiendo llegar al punto que los europeos denominan “APP institucionalizadas”. Las modalidades de APP han adquirido nuevas características en relación con la financiación, formas de acuerdo, distribución de riesgos, etc.

En el caso concreto de Colombia, la figura que vincula a la empresa privada para el desarrollo de obras y prestación de servicios públicos lleva vigente poco más de veinte años (desde la expedición de la Ley 80 de 1993), aunque el artículo 365 de la Constitución de 1991 determina que si bien la prestación de los servicios públicos es inherente a la finalidad social del Estado, dichos servicios podrán ser prestados por particulares, lo cual abrió un espacio para que estos a título privado desarrollen funciones que otrora estaban única y exclusivamente en cabeza del Estado. Pero más importante aún, dicho artículo elimina la posibilidad monopolística estatal en la prestación de ciertos servicios públicos y determina el régimen de libre competencia, eso sí, bajo la supervisión de entes gubernamentales.

Yendo aún más atrás en busca de los antecedentes de la alianza entre Estado y particulares para el desarrollo de obras públicas y prestación de servicios en Colombia, es necesario remontarse a la Constitución de 1886, Carta que estaba basada en el concepto simple y sencillo según el cual el Estado debe lograr los "cometidos esenciales", que consistían primordialmente en su diferenciación de la finalidad de lograr la riqueza, que era tarea de los particulares o del sector privado (Palacio, 2002, p. 21). 
La tarea del Estado se concretaba fundamentalmente en encarnar y desarrollar las funciones propias de la rama legislativa y judicial del poder público, y administrativamente las referentes al manejo del poder de policía y al orden público. El Estado, por lo tanto, no era en esencia un contratante (Palacio, 2002, p. 21).

El fracaso del modelo antes mencionado obedeció, entre muchas razones, a la imposibilidad de los particulares de hacerse cargo de la satisfacción de las tareas sociales y de la atención a la comunidad respecto a sus necesidades básicas, y especialmente de los requerimientos de los grupos menos favorecidos. Esta situación condujo al Estado a asumir una posición más activa, de intervención, regulación y dirección de la prestación de servicios, dejando de lado el papel de simple observador (Palacio, 2002, p. 21).

En tal sentido, el Estado cambió radicalmente de postura y comenzó a desarrollar el concepto de "Estado prestador de servicios públicos", que se materializó con la entrada en vigencia de la reforma constitucional de 1968 y de decretos como el 1050 de 1968 y el 3130 de 1968. Dichas reformas moldearon de tal manera la estructura estatal que permitió que esta asumiera de manera monopólica, exclusiva y excluyente la prestación de los diferentes servicios públicos a través de la contratación estatal, acto en que confluían las diversas formas de participación de los particulares en calidad de contratistas, eso sí, sin que el Estado perdiera su calidad de titular en la prestación del servicio ni la potestad de imponer un estricto control a la actividad pública para evitar la ineficiencia.
Los excesivos controles convirtieron los procesos licitatorios en engorrosos trámites que podían tomar años para ser adjudicados. En el escrito Parámetros constitucionales para la determinación de un régimen jurídico de contratación pública en Colombia, la profesora María Teresa Palacio Jaramillo atribuye la ineficiencia e ineficacia en el desarrollo de la contratación pública a la falta de competencia, ya que al existir un único agente prestador se genera un ambiente de corrupción y letargo por la concentración de poder en una sola cabeza (2002, p. 23).

Al entrar en vigencia la Carta Política de 1991, el modelo de Estado cambió en muchos aspectos, entre ellos el que se utilizaba para los procesos de contratación pública. Se pasó de un modelo en el cual el Estado tenía un manejo exclusivo y excluyente de la prestación de servicios públicos, a un modelo de Estado competitivo (Palacio, 2002, p. 23), donde "la competencia libre se erige como un derecho de todos, obviamente dentro de los límites del bien común y el interés colectivo, así como de los principios de razonabilidad y proporcionalidad que tantas veces ha definido nuestra Corte Constitucional" (sentencia C-398 de 1995), y donde el Estado adopta una postura preponderante dentro del desarrollo de la riqueza y la evolución económica de los particulares, siguiendo lineamientos macroeconómicos propios de la globalización como son: la desregularización, la apertura y la privatización.

De esta manera, y en virtud de la Constitución del 91, se comienzan a dar una serie de desarrollos legales que propenden por el ejercicio 
de los principios establecidos en la nueva Carta Política y que guiarán, en el caso preciso, la contratación estatal. Dichos desarrollos legales se concentran principalmente en la expedición del Nuevo Estatuto de Contratación de la Administración Pública (Ley 80 de 1993), que es ante todo una modificación a códigos fiscales, departamentales y municipales en lo relacionado con la contratación pública. Además, es la expresión de la nueva perspectiva que asume el Estado frente a diversos temas administrativos, es decir, una perspectiva donde se aplican disposiciones civiles y comerciales en temas de contratación pública para estimular la igualdad y la libre competencia.

Como lo expresó el presidente Gaviria en el acto de sanción de la Ley 80 de 1993, esta se sanciona:

Con el fin de adaptar la normatividad a la constitución nacional expedida en 1991 y adecuarla a la necesidad de dotar a las entidades estatales de normas que ofrecieran soluciones a las dificultades que presentara la actividad contractual del Estado, por el excesivo reglamentarismo, la desnaturalización del contrato y las múltiples instancias de revisión y aprobación que caracterizaron su contenido (citado por Betancourt, 1993, p. 5).

Así, la Ley 80 de 1993 estableció diversas formas en las cuales los particulares se hacen parte dentro del desarrollo de obras públicas y prestación de servicios públicos; específicamente el artículo 32 presenta las diferentes modalidades: la concesión, el contrato de obra, la consultoría, la prestación de servicios y las aso- ciaciones entre entidades públicas y privadas sin ánimo de lucro, etc. ${ }^{3}$ El fenómeno de cooperación entre entidades públicas y privadas ha venido evolucionando de manera tal que es clara no solo la relación entre el Estado y los particulares, sino el hecho de que sean los particulares quienes entran a tener la iniciativa y a proponer el desarrollo de obras que al Estado le pueden interesar.

Desde la promulgación de la Ley 1508 se ha entendido que el modelo que más se asemeja al de las App es el de las concesiones, ya que ambas figuras, en principio, autorizan el usufructo de una obra por parte de un particular en contraprestación por la construcción, manejo y mantenimiento de esta. Pero existen divergencias: el esquema de APP a diferencia del contrato de concesión es más riguroso en el tema de estructuración de proyectos, dado que se hace en concordancia con ciertos niveles de servicio y con estándares definidos (Ministerio de Hacienda y Crédito Público y Departamento Nacional de Planeación, 2011, p. 28).

Es necesario resaltar que las fuentes de pago en concesiones y modelos de APP no son iguales. En las concesiones el pago es a través del cobro a los usuarios y eventualmente a través de pagos diferidos del presupuesto público, mientras que en las APP, si bien son a través de recursos del presupuesto público (determinados hasta

3 Posteriormente, la Ley 498 de 1998 en el artículo 95 estableció la asociación entre entidades públicas "con el fin de cooperar en el cumplimiento de funciones administrativas o de prestar conjuntamente servicios que se hallen a su cargo, mediante la celebración de convenios interadministrativos o la conformación de personas jurídicas sin ánimo de lucro". 
un monto máximo del valor de la obra), también lo son en virtud de los negocios conexos a la prestación del servicio (Ministerio de Hacienda y Crédito Público y Departamento Nacional de Planeación, 2011, p. 29). El negocio conexo a la prestación del servicio se constituye cuando en virtud del desarrollo de una obra se comienzan a generar diferentes actividades económicas, lo que permite que dicha obra sea usada de manera más provechosa. Un ejemplo de los negocios conexos a la prestación del servicio se da cuando a un particular se le otorga el desarrollo de una vía y su correspondiente administración, y alrededor de dicha vía se comienza a dar un progreso turístico, residencial, comercial o de cualquier índole, fenómeno que genera un mayor tránsito de vehículos y, en consecuencia, un incremento en los ingresos para el particular que la administra.

Otra diferencia importante se presenta en los requerimientos técnicos de la obra. En las concesiones estos corresponden a requisitos de conservación de la infraestructura y de explotación de los servicios relacionados, cuya regulación está basada en programas de conservación, mientras que en las APP responden a las especificaciones de cada servicio y a indicadores de cumplimiento, lo que demuestra que la estructuración de cada proyecto depende de las condiciones específicas de calidad y servicio determinadas para cada obra en particular, según el servicio que pretenden prestar.

El hecho de que existan ciertas diferencias en las formas de desarrollo y aplicación de las concesiones y de las APP no quiere decir que sean fi- guras desconocidas o ajenas entre sí. De hecho, el artículo 2 de la Ley 1508 de 2012 establece que las concesiones de las que habla la Ley 80 están comprendidas dentro de los esquemas de las APP, y el artículo 3 determina que será aplicable a todos los contratos en los cuales una entidad estatal encargue a un inversionista privado el diseño y construcción de infraestructura y sus servicios asociados o su construcción, reparación o mantenimiento.

Además, los procesos de selección y las reglas para la celebración y ejecución de contratos que supongan la ejecución del modelo de App se rigen por lo dispuesto en las leyes 80 y 1150, salvo en las materias particularmente establecidas en dicha ley.

Entendida la caracterización precisa del modelo APP frente a la concesión, es necesario recalcar el porqué de la necesidad de esta ley en Colombia. En la parte motiva de la Ley 1508 se establece que las App se conciben como el gran aliado del Plan Nacional de Desarrollo, en razón a que impulsarán las diferentes locomotoras de la economía nacional que generarán el desarrollo del sector productivo y social del país, así como optimizar al máximo los recursos públicos.

En la exposición de motivos de la Ley 1508 de 2012 se establecen las siguientes ventajas de las APP:

1. 'La incursión del sector privado en el desarrollo de infraestructura permite tener niveles acelerados de ejecución, ya que el concesionario requiere la certificación de que la obra 
cumple con los niveles de disponibilidad para poder comenzar a percibir ingresos producto de su explotación. Además, la incursión del sector privado en el desarrollo de infraestructura reduce la afectación que se genera a la deuda pública, porque en la mayoría de casos, gran parte de los recursos requeridos para la obra provienen de los particulares.

2. La transferencia de riesgos al sector privado permite el ahorro de recursos públicos. Dado que los particulares asumen el desarrollo de la obra empezando en su planeación, construcción y terminando en su administración, son ellos quienes asumen las responsabilidades por la puesta en funcionamiento de la obra y no el Estado.

3. Se contribuye al crecimiento del mercado de capitales. Esta premisa es muy importante en razón a que es allí, en dicho sector del mercado financiero donde las obras de infraestructura productiva y social encuentran una de sus principales fuentes de financiación.

4. Incentiva la inversión extranjera. Dado que las obras públicas se convierten en un nicho de negocio que puede producir rendimientos interesantes para las empresas extranjeras, los modelos de ApP incentivan el ingreso de dineros para la financiación de obras.

En Colombia la ley ha determinado dos maneras en las que las APP se pueden dar.

\section{A. APP de iniciativa pública}

Son aquellas que se encuentran desarrolladas en el artículo 9 de la Ley 1508. Bajo esta forma de APP las entidades públicas son las que proponen la realización de un proyecto, y los particulares luego de conocerlo entran al proceso de selección para licitar e intentar que se les conceda su realización.

Luego de que la entidad pública da a conocer la apertura de un proceso para la realización de la obra, se procede a la preclasificación de oferentes, proceso donde se valida a los particulares interesados en la adjudicación de la obra. Antes de la apertura formal del proceso la entidad debe haber realizado estudios de carácter técnico, socioeconómico, ambiental, predial, financiero y jurídico acordes con el proyecto. Además, una evaluación estricta de costo beneficio y una clara explicación del por qué la figura de la APP es el mecanismo idóneo para el desarrollo de la obra.

Una vez realizados los estudios técnicos y de viabilidad de la obra, las entidades públicas proceden a hacer la selección objetiva de los oferentes con base en su capacidad financiera, jurídica y de experiencia de inversión, así como a determinar los aportes económicos del Estado.

\section{B. APP de iniciativa privada}

Son aquellas en las cuales los particulares pueden presentar de forma confidencial y en estricta reserva de las entidades, propuestas de proyectos de infraestructura o de prestación de 
servicios asociados, por su propia cuenta y riesgo, es decir, asumiendo la totalidad de los costos de la estructuración. Cuando existan varios proponentes para un mismo proyecto tendrá prioridad en su estudio el primero que radique la oferta ante la entidad estatal competente, si posteriormente es declarada como viable (art. 20, Ley 1508).

El proceso que debe seguir el proponente es riguroso y tiene varias etapas que constituyen la estructuración de la propuesta y de la obra como tal: prefactibilidad, factibilidad, revisión previa de la iniciativa privada y evaluación de la iniciativa privada.

Esta sucesión de etapas tiene como razón fundante de ser, el concepto ya mencionado de previsión y planeación. Dicho concepto propende por determinar todas las posibles contingencias que el proyecto pueda arrojar durante su desarrollo y ejecución. Es también una garantía para el ente estatal, ya que permite avizorar las posibles eventualidades, y es una herramienta para el actor privado, puesto que le permite conocer al detalle todo el proyecto y de esa manera realizar un análisis de costos más riguroso.

Estas etapas de planeación pueden constituirse en elementos tanto positivos como negativos para el actor privado. Negativos en el sentido en que los costos en los que incurre son altísimos y no tiene ninguna certeza de que el ente estatal dará vía libre a su propuesta. Por tal motivo, los proponentes privados están obligados a tener un gran músculo financiero y una alta seguridad sobre el proyecto a proponer.
En caso que el proyecto sea valorado y aceptado por parte de la entidad pública se pueden dar dos circunstancias en su realización: 1) Se requieren recursos públicos provenientes del Presupuesto General de la Nación, de entidades territoriales o de otros fondos públicos, que podrán ascender hasta el 20\% del valor total de la obra según el tope impuesto en el artículo 17 de la Ley 1508. Dada esta circunstancia, habrá que abrir licitación pública y otros oferentes podrán participar en la realización del proyecto; 2) No se Requieren recursos públicos. Respetando el principio de publicidad la entidad pública deberá publicar en el Sistema Electrónico de Contratación Pública (SECOP) la minuta del contrato y sus anexos. Transcurrido el plazo de convocatoria, si no se presentan otros proponentes la entidad procederá a contratar de manera directa con el proponente original. Si existen terceros interesados que cumplan con las condiciones establecidas en la publicación de la entidad, ante todo con el requisito de realizar la obra sin requerir recursos públicos, deberán garantizar la presentación de la iniciativa mediante una póliza de seguro, un aval bancario u otro medio autorizado por ley.

Por su parte, la entidad deberá abrir un proceso de selección abreviada de menor cuantía con preclasificación, para la selección del contratista. Si como resultado de este proceso la mejor propuesta no es la del originador, este tendrá derecho a presentar una oferta que mejore la del proponente mejor calificado, en un plazo máximo de diez (10) días hábiles (art. 20, Ley 1508). 
Antes de exponer la forma de financiación que la Ley 1508 establece para las APP, es necesario recalcar que esta figura también está enfocada en generar desarrollo en la prestación de los servicios que no tienen un carácter eminentemente productivo, motivo por el cual la mejora de la infraestructura social es un parámetro importante para evaluar la utilidad de esta modalidad de contratación.

La infraestructura social está referida a todas las instituciones requeridas para mantener el estándar económico, social, cultural y de salud de un país. No se trata del diseño, construcción, mantenimiento o administración de obras que se desarrollen con la única finalidad de generar un negocio lucrativo para los particulares y la creación de una infraestructura para el Estado, sino de un modelo en el que los particulares se hacen parte para apoyar al Estado en la consecución de ciertos postulados constitucionales de prestación de servicios y garantía de los derechos de los ciudadanos.

Por tal motivo, la infraestructura social es aquella que está conformada por las obras y servicios relacionados, que permiten incrementar el capital social de una comunidad y la posibilidad de acceder a mayores servicios o de mejor calidad. Según el Departamento Nacional de Planeación (2013) hacen parte de la infraestructura social sectores y proyectos como:

- Salud (hospitales, centros de salud primaria).

- Defensa y penitenciario (cárceles, centros de detención preventiva).
- Edificación pública (edificación de oficinas públicas y del poder judicial).

- Deportivo y cultural (recintos deportivos, artísticos y culturales).

- Ambiental (áreas naturales protegidas).

- Educación (preescolar, básica, media y superior).

El desarrollo de obras encaminadas a mejorar la infraestructura social sigue los mismos lineamientos procesales licitatorios y de adjudicación que aplican para la infraestructura productiva.

\section{Breve aclaración sobre las fuentes de financiación de las APP en Colombia}

Una vez expuesto que en Colombia las APP se pueden constituir tanto por iniciativa privada como por iniciativa pública, es necesario ocuparnos de cómo la ley determina la financiación de los proyectos a realizar.

La Ley 1508, artículo 12 parágrafo 2, establece como requisito para la selección objetiva de los oferentes (sin importar si son APP de iniciativa pública o privada) que estos demuestren su capacidad financiera o de financiación, además de su capacidad jurídica y su experiencia en la inversión y estructuración de proyectos. Demostrar dicha capacidad financiera significa que el oferente puede determinar con claridad el origen de los dineros con los cuales desarrollará la obra y su disposición, además de establecer si hay requerimiento de inversión pública o se constituye en su totalidad con base en inversión privada. 
Si es una APP con inversión pública, el oferente debe establecer los órganos que desembolsarán dichos recursos, es decir, si son entidades centralizadas, descentralizadas o si dicha inversión proviene del sistema general de participaciones, y el monto del desembolso teniendo presente que de acuerdo con el artículo 17 de la Ley 1508 este no puede superar el 20\% del presupuesto estimado de inversión del proyecto. Si por el contrario los recursos son netamente inversiones privadas, el oferente está obligado a determinar si el carácter de las inversiones es de capital, de endeudamiento bancario o de endeudamiento de mercado de capitales.

\section{Diferentes aspectos, comentarios y controversias generadas por la implementación del modelo de APP en Colombia}

\section{Controversia generada por la calidad de los aportes públicos frente al tope impuesto por la Ley 1508 en su artículo 17}

La financiación de los proyectos ha sido uno de los temas más debatidos de la ley en comento, más concretamente el hecho de que dado el caso que se constituya una APP de iniciativa privada con inversión pública los aportes de la entidad pública solo puedan llegar hasta del 20\% del presupuesto estimado de la inversión del proyecto.

Una de las diferentes incógnitas en relación con este tema es aquella en la cual se cuestiona el carácter que tienen las retribuciones o repagos que hace el Estado cuando la obra ya está concluida, debido a que el art. 17 es explícito en determinar que: "Ios recursos del Presupuesto General de la Nación, de las entidades territoriales o de otros fondos públicos, no podrán ser superiores al $20 \%$ del presupuesto estimado de inversión del proyecto", y por ende si hay un desembolso del Presupuesto General de la Nación posterior al aporte realizado para el desarrollo del proyecto se estaría sobrepasando el límite del $20 \%$.

Algunos críticos de la ley argumentan que no existe claridad en la determinación de los aportes públicos que irían destinados a cubrir parte o la totalidad del $20 \%$ que puede llegar a solicitar el privado para el desarrollo de la obra o prestación del servicio, y aquellos que se hacen como simple ejercicio de la obra y de su funcionamiento.

Para aclarar la situación que aquí se expone, es útil un ejemplo. La situación es la siguiente:

A un particular, una entidad pública a través del modelo APP de iniciativa pública le ha encomendado el desarrollo (provisión de los bienes públicos y sus servicios relacionados) de una cárcel. En dicho proyecto se necesitarán aportes provenientes del Presupuesto General de la Nación, que no pueden ser superiores al $20 \%$ del presupuesto estimado de inversión, según el artículo 17 de la Ley 1508.

El tope máximo de aportes provenientes del Presupuesto General de la Nación ya fue entregado para el desarrollo de la obra. El proyecto se encuentra en pleno funcionamiento, es decir, 
todas las unidades funcionales de infraestructura ${ }^{4}$ operan acorde con lo establecido en los estándares de calidad ${ }^{5} \mathrm{y}$ los niveles de servicio. ${ }^{6}$ Hay plena disponibilidad de la infraestructura. ${ }^{7}$

Como la cárcel es una infraestructura social, el Estado debe pagar una cuota al particular por cada recluso/interno que ingresa al centro penitenciario. De esta manera, el particular empieza a recibir ingresos que le permiten ir pagando la deuda en la que incurrió para la construcción y administración de la cárcel, además del dinero que le corresponde como utilidad, ya que en últimas es un negocio del que debe sacar la rentabilidad y retribución ${ }^{8}$ propia de los proyectos de APP.

Bajo los anteriores postulados, vale preguntarse si las cuotas que paga el Estado por cada recluso en el caso del ejemplo (y que son dineros públicos) deben contarse dentro del $20 \%$ que por

4 Según el artículo 2 del Decreto 1467 por medio del cual se reglamenta la Ley 1508 de 2012, una unidad funcional de infraestructura es el conjunto de estructuras de ingeniería e instalaciones indispensables para la prestación de servicios con independencia funcional, que le permitirán funcionar y operar de forma individual cumpliendo estándares de calidad y niveles de servicio relacionados con la satisfacción de la necesidad que sustenta la ejecución del proyecto de APP.

5 Son las características mínimas e inherentes al bien o servicio objeto del contrato (art. 2 del Decreto 1467 por medio del cual se reglamenta la Ley 1508 de 2012).

6 Condiciones o exigencias que se establecen para un indicador de gestión, para definir el alcance y las características de los servicios que serán provistos (art. 2 del Decreto 1467).

7 De acuerdo con el artículo 4 del Decreto 1467 ya precisado, hay disponibilidad de la infraestructura cuando está en uso y cumple con los niveles de servicio y los estándares de calidad establecidos en el respectivo contrato.

8 El derecho de retribución en proyectos de asociación público privada está condicionado, según el artículo 5 del Decreto 1467, a la disponibilidad de la infraestructura, al cumplimiento de niveles de servicio y a estándares de calidad. ley puede darle al particular para el desarrollo de la App. De ser así, se estaría violando el artículo 17 de la Ley 1508, ya que los dineros provenientes del Presupuesto General de la Nación ya fueron invertidos en la fase de construcción y desarrollo de la obra, y muy posiblemente ya se llegó al tope de inversión de recursos públicos, es decir, al $20 \%$ del presupuesto de inversión de la obra.

Por tal motivo, y siguiendo la tesis de la falta de claridad de este artículo que señalan algunos críticos, cada vez que el Estado haga una retribución al particular por el proyecto de APP estaría sobrepasando el tope del $20 \%$, y solo lo dejaría de violar en el momento en que se cumpla el plazo de ejecución del contrato de APP, que puede ser hasta de treinta años (art. 5 Ley 1508) o se dejen de hacer las retribuciones.

En concepto de quien escribe este documento, dicha situación está expresamente resuelta, con base en los siguientes argumentos.

1. Sería un contrasentido seguir la argumentación según la cual la Ley 1508 fue imprecisa y oscura al determinar cuándo los aportes públicos deben contabilizarse dentro del 20\% y cuándo son simples retribuciones al servicio, ya que confundir el título de estas erogaciones desembocaría en la imposibilidad de constituir y desarrollar APP de infraestructura social, dado que en esos casos el Estado o los entes territoriales son los únicos que realizan pagos por los servicios que las obras de App prestan. Valga decir que dichos pagos son dinero público proveniente del Presupuesto General de la Nación. 
De no discriminar los conceptos por los cuales ingresan los dineros a una APP, es decir, entre aportes o retribuciones por la prestación de los servicios, nos enfrentaríamos indudablemente a un escenario en el que sería imposible no superar los topes establecidos, ya que las retribuciones que se haga durante toda la vigencia de la APP se contarían como aportes, que en últimas siempre sobrepasarían el $20 \%$ que la ley estableció como tope.

También hay que tener en cuenta que en muchas ocasiones habrá APP que tengan ingresos mixtos, es decir, que en ejercicio del desarrollo de la ApP reciban retribuciones de sujetos de carácter privado (dineros privados) y sujetos de carácter público (dineros públicos). Es el caso de una vía que para su diseño, construcción, funcionamiento, etc., haya necesitado aportes provenientes del Presupuesto General de la Nación, y que una vez en servicio comience a producir dinero por concepto del cobro de peajes, ingreso que se constituirá en retribución para el particular que desarrolla la APP. Si luego de alcanzado el tope de los recursos otorgados por el Estado (20\% del presupuesto de la inversión total del proyecto), por dicha vía llegan a pasar vehículos de alguna entidad pública y pagan el peaje con dineros de caja menor (que a la final son dineros públicos), estaríamos enfrentados a un escenario en el que constantemente se estaría violando el tope establecido.

Por tal razón, el privado que tiene a cargo la APP estaría en la obligación de discriminar no solo si cada vehículo que transita por la vía pertenece a un particular o a una entidad pública, sino incluso en el caso más extremo y complejo, en la obligación de determinar si la persona que transita por la vía está pagando con dineros propios o de alguna entidad, cosa que es absurda e imposible de conocer en su totalidad, ya que supondría un desgaste administrativo.

2. En segundo lugar, porque como lo expresa el artículo 10 del Decreto 1467 de 2012 “los recursos generados por la explotación económica del proyecto no son considerados desembolsos de recursos públicos", lo cual significa que sin importar bajo qué modelo de App se esté desarrollando la obra, ni cuál sea esta, los dineros producidos en relación con su explotación no se pueden tomar como desembolsos a título de recursos públicos. De esta manera la ley está haciendo una calificación o diferenciación tácita de los recursos que ingresan a la APP, ya que es clara en determinar que los recursos generados en virtud de la explotación del proyecto no tienen la misma calidad que aquellos que se hacen como aportes, que en últimas son los que no pueden superar el tope máximo por ella establecido.

Dicho lo anterior, en criterio del autor la discusión sobre esta problemática está zanjada. El mismo Decreto 1467 de 2012 la resolvió al establecer que durante el periodo de explotación del proyecto los dineros que ingresen provenientes del Presupuesto General de la Nación, del presupuesto de las entidades territoriales, entidades descentralizadas o de otros fondos públicos no se pueden asumir como aportes para el desarrollo del proyecto. 


\section{Diseño de la Ley 1508 como traba para el desarrollo de los proyectos de APP de infraestructura social}

El modelo de APp que entró en ejercicio a Colombia por medio de la Ley 1508 trae consigo muchos elementos que permiten resolver grandes problemáticas que aquejaban al Estado en temas de contratación, entre otros, su estrictez en el tema de aportes, prórrogas y adiciones. Además, tiene un marco reglamentario claro en torno a la estructuración de proyectos en lo concerniente a su viabilidad. El hecho de establecer unas rigurosas etapas de prefactibilidad y factibilidad así lo demuestran.

Dichas medidas a primera vista son supremamente beneficiosas para el Estado y más que todo para el erario público, ya que la falta de rigor generaba que los proyectos costaran mucho más de lo que se proponían en un principio y que tuvieran una pésima planeación, que en últimas se traducía en pérdidas económicas para las entidades y para el Estado. Pero también es cierto que estas medidas han generado una situación inusual, que ha desembocado en la dificultad de los particulares para desarrollar proyectos de APP de infraestructura social.

En primer lugar, porque cuando los particulares estructuran proyectos para el desarrollo de infraestructura social a través de APP de iniciativa privada deben asumir la totalidad de los costos a su cuenta y riesgo: los estudios técnicos, socioeconómicos, ambientales, financieros y jurídicos (art. 11 Ley 1508); las evaluaciones de costo beneficio del proyecto y la descripción completa de este, incluyendo el diseño mínimo en etapa de prefactibilidad; construcción, operación, mantenimiento, organización y explotación, alcance del proyecto, estudio de demanda en etapa de prefactibilidad, especificaciones del proyecto, su costo estimado y las fuentes de financiación (art. 14 Ley 1508).

Todos estos requisitos impuestos por ley en etapa de prefactibilidad constituyen una carga supremamente pesada para los particulares, ya que la realización de todos los estudios supone un gasto económico gigante para los posibles proponentes y dificulta darle un cierre financiero positivo al momento de realizar la planeación.

Dado que la administración puede o no aceptar la propuesta que se haga con base en los estudios antes realizados, el particular corre un riesgo altísimo de perder la inversión en dichos estudios, ya que la administración no está obligada a reconocerlos económicamente.

Es entonces más beneficioso para el particular esperar a que la administración, en desarrollo de un proyecto de APP de iniciativa pública, incurra en todos los gastos de prefactibilidad estudios, evaluación de costos, justificación, etc.- que son requisito para abrir el proceso de selección de contratistas, y ahí sí presentarse como oferente.

En todo caso, y volviendo al escenario en el cual un particular propone constituir una APP de iniciativa privada para infraestructura social, persistirían los problemas para el desarrollo de esta. Lo anterior en razón a que, a diferencia de las APP 
de infraestructura productiva, las APP de infraestructura social tienen un margen muy rígido de creación de utilidad. Es decir, en contraposición con las APP de infraestructura productiva donde los márgenes de ganancia pueden aumentar debido el incremento de negocios conexos que generan una mayor variabilidad en los ingresos, aumentando la velocidad del retorno de la inversión y creando más utilidad, las APP de infraestructura social están desde el momento de su estructuración diseñadas de manera tal que la variabilidad en los ingresos es muy poca, es decir, el particular sabe desde el principio cuánto va a ganar por el desarrollo del proyecto y qué utilidad este va a arrojar.

Dicha falta de variabilidad en los ingresos tiene un efecto, y es que si bien el proyecto como negocio es seguro, puede no llegar a ser atractivo en razón a que los particulares entran a esta clase de negocios con la finalidad de ganar dinero, y bajo este modelo la utilidad está circunscrita a unos márgenes poco variables que los hacen poco llamativos. Esta situación podría generar en los inversionistas la inquietud por conocer si los dineros que disponen para el desarrollo del proyecto podrían tener mayores rendimientos en otros tipos de inversión.

Existe también una razón política que desde ya se puede avizorar para argumentar la dificultad que tendrán las APP de iniciativa privada para el desarrollo de infraestructura social: la falta de interés de los entes territoriales (alcaldías y gobernaciones), ya que el hecho de que esta se realice con dineros privados (en mayor medida) les impide tanto a alcaldes como a goberna- dores ejecutar el presupuesto departamental o municipal, del cual tantos réditos devienen y sobre el cual se guardan demasiados intereses.

Como última observación sobre las dificultades que las APP de iniciativa privada deberán afrontar para el desarrollo de infraestructura social, se encuentra la disposición del parágrafo 2 , artículo 3 de la Ley 1508 según la cual "aquellos sectores y entidades para las cuales existan normas especiales que regulen la vinculación de capital privado para el desarrollo de proyectos deberán seguir rigiéndose por dichas normas." Esta disposición afecta también a las APP de infraestructura productiva, pero se pensaría que los sectores a los cuales está enfocada la infraestructura social son más propensos a tener una normativa especial, que pueda llegar a afectar, torpedear o imposibilitar la aplicación del modelo de APP.

\section{Cruce de proyectos en la infraestructura vial desarrollada a través de APP}

Si bien las App han sido concebidas en Colombia para desarrollar cualquier tipo de infraestructura, y para la prestación de diversos tipos de servicios de manera más efectiva y con mayor calidad, no es un secreto que una de las grandes finalidades inmediatas de la implementación de esta figura es la mejora de la infraestructura vial del país. Por tal motivo, el desarrollo de los proyectos que componen las denominadas Autopistas para la Prosperidad o de Cuarta Generación es una prioridad para el Gobierno actual. 
Son cuantiosos los recursos que invertirá la Nación en el desarrollo de estas obras: ascienden a 47 billones de pesos e incluso se ha determinado que los recursos provenientes de la venta de Isagen serán destinados en su totalidad a las autopistas de cuarta generación (El Colombiano, 2014).

El desarrollo vial del país generará mayor inversión y elevará los niveles de competitividad, pero desde ya se avizoran problemas jurídicos para los tramos que ya están adjudicados (Pacífico 1, 2 y 3 y la vía Cartagena-Barranquilla). Uno de los problemas jurídicos que desde ya se ve venir para la construcción de estas obras consiste en que sectores del trazado de la vía se cruzan con otras concesiones viales ya adjudicadas hace algunos años.

Frente a esta situación, se podrían prever conflictos por motivos técnicos de construcción, ya que no está claro quién tiene derechos para intervenir los tramos donde hay cruces de concesiones ni bajo qué parámetros. En un principio, la tensión es evidente entre los derechos de los concesionarios anteriores y los de los adjudicatarios de las autopistas de cuarta generación. Se podría prever que en procura del mejoramiento vial del país y de la uniformidad técnica de las nuevas vías, se le conceda a los nuevos adjudicatarios el derecho para intervenir los cruces viales bajo sus parámetros.

Pero de la mencionada situación se desprenderán, ineludiblemente, los alegatos de la concesión antigua, los cuales muy posiblemente irán encaminados a demandar al Estado por la crea- ción de un desequilibrio contractual por sustracción de tramos de obra, o como mínimo por los costos de la modificación del contrato.

\section{CONCLUSIONES}

En los últimos años, y a raíz del desarrollo económico que se ha dado en el país, Colombia ha empezado a cambiar en muchos sentidos, entre ellos en la forma de desarrollar su infraestructura. La generación e impulso de figuras como las APP son una muestra clara de que optó por un modelo de competitividad e inclusión de la empresa privada y de que a partir de la expedición de la Ley 1508 de 2012 avanza por una senda que propende por el desarrollo eficiente, de calidad y productivo de los medios necesarios para el desarrollo social y económico.

Si bien es un paso en la dirección correcta, todavía subsisten errores, incertidumbres y problemáticas que con el tiempo y la práctica se deben ir solucionando, como en su momento lo hicieron las naciones que nos antecedieron en estos modelos de desarrollo y que hoy en día los aplican exitosamente con altos niveles de experiencia y eficacia.

La meta de la Ley 1508 debe ser, entonces, generar una infraestructura que permita ante todo robustecer la economía colombiana, ayudando a la competitividad de todos los tipos de empresas públicas y privadas, además, y no menos importante, impulsar una infraestructura social que le permita al país avanzar en las metas que el Estado se propone frente a los ciudadanos. 
Esta ley de App permitirá tener un país más competitivo, más equitativo, con mejores índices de empleo, con importantes niveles de inversión que al final se traduzcan en prosperidad, y sobre todo un país más desarrollado, donde los estándares de calidad de vida mejoren para todos.

\section{Referencias}

Ariño Ortiz, G. (2010). El contrato de colaboración público privada. En F. de Vivero Arciniegas (comp.), Reforma al régimen de contratación estatal. Bogotá: Ediciones Uniandes.

Betancourt Cuartas, J. (1993). Nuevo estatuto de la contratación administrativa. Medellín: Biblioteca Jurídica Diké.

Borja Colón de Carvajal, F. (6 de noviembre de 2013). El contrato de colaboración entre el sector público y el sector privado en el ordenamiento jurídico español: orígenes, características y naturaleza de una experiencia exitosa. Recuperado de Noticias Jurídicas: http://noticias.juridicas.com/ articulos/15-Derecho\%20Administrativo/200910-43829474723947563.html.

Congreso de la República de Colombia. Ley 1508 de 2012.

Congreso de la República de Colombia. Ley 498 de 1998.

Congreso de la República de Colombia. Ley 80 de 1993.
Consejo Nacional de Política Económica y Social. (28 de septiembre de 2009). Conpes 3615 de 2009.

Corte Constitucional. Sentencia C-398 de 1995. M. P.: José Gregorio Hernández.

Departamento Nacional de Planeación. (s. f.). Abecé asociaciones público privadas. Recuperado de DNP: https://www.dnp.gov.co/ LinkClick.aspx?fileticket=D10COgSvKkQ\%3D \&tabid=1533

El Colombiano.com. (21 de julio de 2014). Recursos de venta de Isagen se usarán en vías 4G desde septiembre. [En línea]. Recuperado de: http://www.elcolombiano.com/ BancoConocimiento/R/recursos_de_venta_ de_isagen_se_usaran_en_vias_4g_desde_ septiembre/recursos_de_venta_de_isagen_ se_usaran_en_vias_4g_desde_septiembre. asp

Greve, C. (2010). Public-Private Partnership in Bussines and Government. En D. Cohen, W. Grant y G. Wilson (Edits.), The Oxford Handbook of Business and Goverment. Oxford: Oxford University Press.

Grimsey, D. y Lewis, M. K. Public Private Partnership. The worldwide revolution in infrastructure provision and project finance. Massachusetts: Eduard Elgar Publishing, Inc.

Jordana, J. y Levi-Faur, D. (Eds.) (2004). The politics of regulation: Institutions and regulatory reforms for the age of governance. Cornwall: MPG Books Ltd. 
Ministerio de Hacienda y Crédito Público y Departamento Nacional de Planeación. (Diciembre de 2011). Guía de buenas prácticas para la ejecución de proyectos de asociación público privada. Bogotá, D. C.: Autores.

Palacio Jaramillo, M. T. (2002). Parámetros constitucionales para la determinación de un régimen jurídico de contratación pública en Colombia. Revista de Derecho Público, (14). Bogotá: Universidad de los Andes.

Rodal, A. y Mulder, N. (1992). Partnership, devolution and power sharing: issues and implications for management. Optimun: The Journal of Public Sector Management (24).

Taylor, J. (1999). Glosario de economía. (J. Coro Pando, Trad.). Bogotá: Compañía Editorial Continental.
The National Council for Public-Private Partnership. (Abril de 1999). Types of Partnerships. Washington: NCPPP. Recuperado de: http:// www.ncppp.org/ppp-basics/types-of-partnerships/

Villanacourt Rosenau, P. (2000). Public-Private Policy Partnership. Massachusetts: Massachusetts Institute of Technology. Sage Publications.

Yescombe, E. R. (2011). Public-Private Partnership: Principles of Policy and Finance. London: Butterworth-Heinemann, Elsevier LTD. Publications. 